\section{Meningococcal chest pain}

\author{
Kenneth Hodson MB Umakant Dave MRCP $^{1}$ \\ Ann Lewis MSc FRCPath²
}

J R Soc Med 2004;97:434-435

Meningococcal disease is potentially lethal if not quickly treated. Familiar presentations are meningitis and septicaemia; less familiar are pericarditis, arthritis and pneumonia.

\section{CASE HISTORY}

A Nigerian man of 26 who had long been resident in the UK without travelling abroad was admitted after 24 hours of left sided pleuritic chest pain, fever and general malaise. He had previously been fit and well. On examination the only noteworthy finding was a temperature of $39.5^{\circ} \mathrm{C}$. His white cell count was $16.9 \times 10^{9} / \mathrm{L}$, C-reactive protein was $137 \mathrm{mg} / \mathrm{L}$, and there were slight increases in creatinine $(135 \mu \mathrm{mol} / \mathrm{L})$, bilirubin $(36 \mu \mathrm{mol} / \mathrm{L})$, aspartate aminotransferase $(44 \mathrm{iu} / \mathrm{L})$, gamma-glutamyl transpeptidase $(124 \mathrm{iu} / \mathrm{L})$, alkaline phosphatase $(67 \mathrm{iu} / \mathrm{L})$ and creatine kinase $(311 \mathrm{iu} / \mathrm{L})$. Troponin-T was normal. Initial electrocardiograms showed widespread 'saddle-shaped' ST-elevation (Figure 1) consistent with acute pericarditis. In view of the mild renal impairment and deranged liver function tests, a possible unifying diagnosis was an atypical pneumonia. Therefore, once blood had been taken for culture, he was treated with amoxicillin, clarithromycin and ibuprofen. Over the next few hours the patient became drowsy, complaining of headache and photophobia. On examination he now showed meningism, with a positive Kernig's sign. There was no papilloedema. The presumed diagnosis was meningitis and he was started on intravenous benzyl penicillin and cefotaxime. An unenhanced CT of the head showed no abnormality, so lumbar puncture was performed. The opening pressure exceeded $40 \mathrm{cmH}_{2} \mathrm{O}$. The cerebrospinal fluid protein was high $(4.4 \mathrm{~g} / \mathrm{L})$ and the glucose low $(0.1 \mathrm{mmol} / \mathrm{L}$ when plasma glucose was $10.2 \mathrm{mmol} / \mathrm{L}$ ). The white cell count was $2400 / \mu \mathrm{L}$, predominantly neutrophils. Gram stain for organisms was negative as was India-ink stain for cryptococcus. Specimens were sent for polymerase chain reaction (PCR) testing for meningococcus and Mycobacterium tuberculosis. Five days later, PCR tests on the cerebrospinal fluid were positive for group B meningococcus infection. Further typing was not possible since the blood cultures taken on admission did not yield bacterial growth. Benzyl penicillin and cefotaxine were continued and the meningism resolved over the next few days; however, pericarditis persisted, with evolving ST-segment elevation. He now had a pericardial rub, and on day 7 troponin- $\mathrm{T}$ was raised at $0.12 \mu \mathrm{g} / \mathrm{L}$ (normal <0.01), suggesting myocardial involvement. An echocardiogram showed bright pericardium with a small effusion (Figure 2). Antibiotics were continued for twelve days. A further

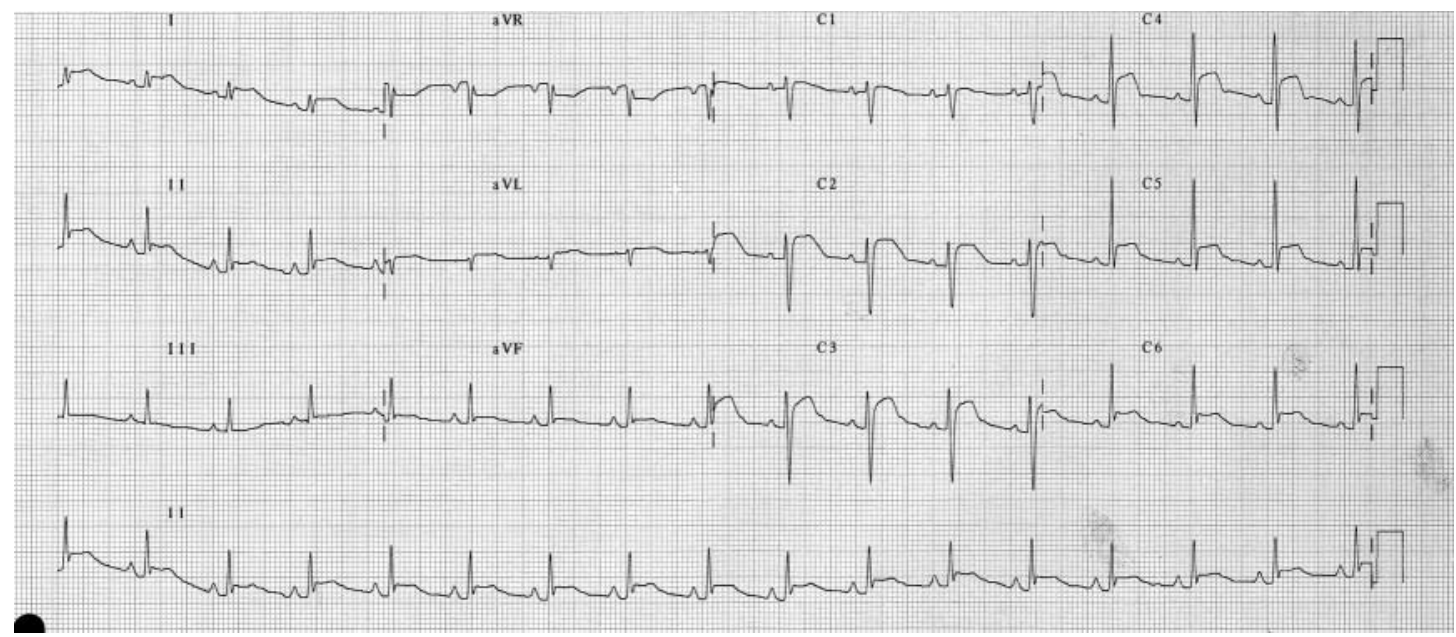

Figure 1 Admission ECG

Departments of ${ }^{1}$ Medicine and ${ }^{2}$ Microbiology, Morriston Hospital, Swansea

SA6 6NL, Wales, UK

Correspondence to: Dr K Hodson

E-mail: drkkhodson@aol.com 


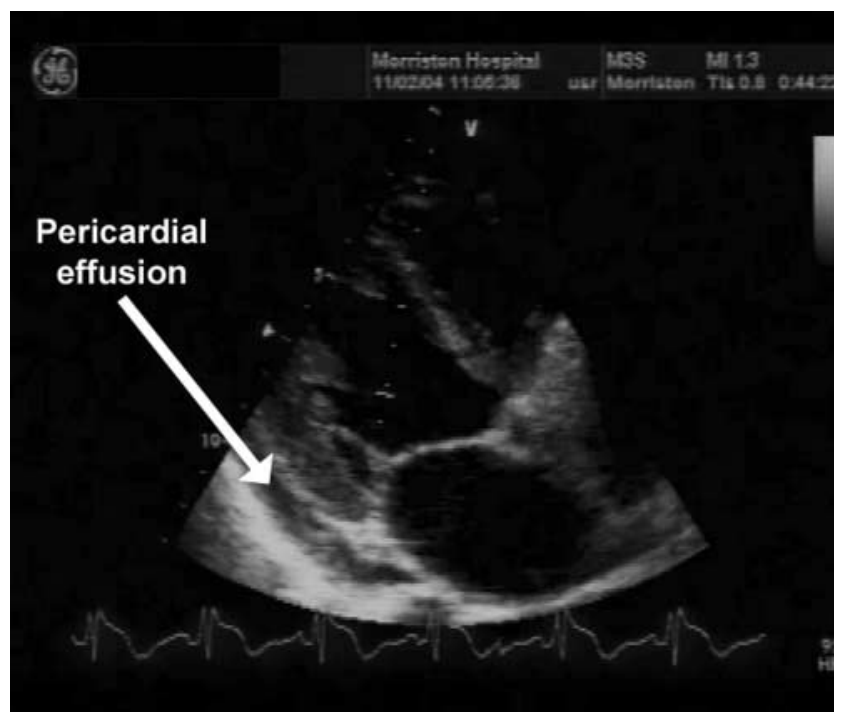

Figure 2 Echocardiogram

echocardiogram on day 9 showed a persistent small pericardial effusion.

\section{COMMENT}

Meningococcal disease (infection with Neisseria meningitidis) presents with meningitis in up to $50 \%$ of cases and with septicaemia (with or without meningitis) in $5-20 \%{ }^{1}$ According to a 1979 review by Laird et al., ${ }^{2}$ symptomatic pericarditis occurs in under $1 \%$ of patients with meningitis. Its rarity is confirmed by recent data from France: meningococcal pericarditis was identified in just 13 cases out of 2091 reported to the National Reference Centre for Meningococcal Disease (Paris). ${ }^{3}$ Meningococcal pericarditis can be classified into three distinct groups. ${ }^{4}$ Disseminated meningococcal disease with pericarditis is due to direct pericardial invasion by blood-borne $N$. meningitidis; pericarditis occurs within 7 days of infection. Isolated meningococcal pericarditis is pericardial infection without meningitis/meningococcaemia. Reactive meningococcal pericarditis is a late sequel (6-16 days) to meningococcal infection and is thought to be due to circulating immune complexes.

The patient described here comes into the first category; the blood cultures taken at presentation were probably false-negatives. In previous case reports of this association, the first manifestations were nearly always those of meningitis, pericarditis being identified later by routine electrocardiography or by detection of a pericardial rub. Chest pain is seldom a feature. ${ }^{2}$ We have found only two reports of the sequence described here-pericarditis preceding widespread meningococcal disease.
A final point concerns pericarditis as a cause of raised troponin-T. This case serves as reminder that chest pain, ST changes and a positive troponin do not always signify an acute coronary syndrome.

\section{REFERENCES}

1 Rosenstein NE, Perkins BA, Stephens DS, Popovic T, Hughes JM. Meningococcal disease. N Engl J Med 2001;344:1378-88

2 Laird WP, Nelson JD, Huffines FD. The frequency of pericardial effusions in bacterial meningitis. Pediatrics 1979;63:764-70

3 Vienne P, Ducos-Galand M, Guiyoule A, et al. The role of particular strains of Neisseria meningitis in meningococcal arthritis, pericarditis and pneumonia. Clin Infect Dis 2003;37:1639-42

4 Finkelstein Y, Adler Y, Nussinovitch M, Varsano I, Amir J. A new classification of pericarditis associated with meningococcal infection. Eur J Pediatr 1997;156:585-8

5 Wilks D, Sutters M, Sissons JGP, Rubenstein D. Group C meningococcal meningitis presenting as acute pericarditis. Eur $J$ Clin Microbiol Infect Dis 1993;12:478-9

6 Brasier AR, Macklis JD, Vaughan D, Warner L, Kirshenbaum JM. Myopericarditis as an initial presentation of meningococcemia: unusual manifestation of infection with serotype W135. Am J Med 1987;82:641-3

\section{Bilateral spontaneous pneumothorax in a cannabis smoker}

\author{
Kathryn Goodyear MRCP Diane Laws MRCP \\ Jonathan Turner QHP FRCP
}

J R Soc Med 2004;97:435-436

Simultaneous bilateral spontaneous pneumothorax is a rare but serious cause of respiratory distress. A possible link with cannabis use highlights the importance of eliciting a full drug history.

\section{CASE HISTORY}

A man aged 23 came to accident and emergency in severe respiratory distress. After two weeks of cough he had become short of breath with pleuritic chest pain. There was no medical history of note and he was not on any regular medication. Later he told us he had smoked cannabis since

Department of Thoracic Medicine, Royal Bournemouth Hospital, Bournemouth BH7 7DW, UK

Correspondence to: Dr K Goodyear

E-mail: kgoodyear@doctors.org.uk 